\title{
Influence of Moringa oleifera leaves on atherogenic lipids and glycaemia evolution in HIV-infected and uninfected malnourished patients
}

\author{
Amivi TÉTÉ-BÉNISSAN ${ }^{*}$, ML Akossiwoa QUASHIE², Koko LAWSON-EVI ${ }^{3}$, Kissao GNANDI ${ }^{4}$, \\ Kouami KOKOU ${ }^{5}$ and Messanvi GBÉASSOR ${ }^{1}$ \\ 1 Laboratoire de Physiologie et de Pharmacologie, FDS, Université de Lomé, (Togo). \\ 2Laboratoire de Physiologie et Biotechnologies végétales, FDS, Université de Lomé, (Togo) \\ ${ }^{3}$ Service de Pédiatrie CHU Tokoin, Lomé, (Togo) \\ ${ }^{4}$ Laboratoire de Géochimie, FDS, Université de Lomé, (Togo) \\ ${ }^{5}$ Laboratoire de Botanique et Écologie Végétale, FDS, Université de Lomé, (Togo) \\ ${ }^{*}$ Corresponding author E-mail: ateteben@tg.refer.org / tetebenissancolette@yahoo.fr \\ Tél. : 00 (228) 900384 02/ 00 (228) 223646 38, Fax: 00 (228) 22258784 / 00 (228) 22218595. \\ Original submitted in on 20th November 2012. Published online at www.m.elewa.org on $27^{\text {th }}$ February 2013.
}

\begin{abstract}
Objectives: The study evaluated mineral composition of "Togolese ecotype" of Moringa oleifera leaves and its effect on anthropometric parameters, atherogenic lipids and glycaemia during nutritional recovery in HIV negative and HIV positive malnourished patients after daily use of the leaves powder.

Methodology and results: Patients aged from 12 months to 8 years, consumed every day for 15 weeks the leaves powder. Results showed that powder is rich in proteins, micronutrients and induced BMI increase in both patients $(p \leq 0.001)$. Biochemical parameters determination showed decrease in total cholesterol, triglycerides, LDL-cholesterol ( $p \leq 0.01$ ), atherogenicity index (Al) correlated with HDL-cholesterol increase $(p \leq 0.001)$ in HIV negative. Increase in triglycerides, LDL-cholesterol, $\mathrm{Al}(\mathrm{p} \leq 0.001)$ correlated with HDLcholesterol decrease $(p \leq 0.001)$ is observed in HIV positive. Total cholesterol decreased more in HIV positive asymptomatic and increased in patients treated with ARV drugs ( $p \leq 0.0001)$. Glycaemia level is decreased in both patients of the study.

Conclusion and application of findings: This study confirms higher concentrations of proteins, micronutrients, hypolipidemic potential and hypocholesterolemic activity of $M$. oleifera leaves. This explained nutritional recovery and reduction of atherogenic lipids. Positive effect of the powder on cholesterol metabolism is due to beta-sitosterol, bioactive phytoconstituent of the leaves which fixed LDL particles and thought to be through the lowering significantly of their plasma concentrations. Reduction of glycaemia in both patients confirms also hypoglycemic properties of leaves with high concentration of polyphenols and antioxydants. The lowering of atherogenic risk and glycaemia after regular consumption of M. oleifera leaves powder is more significant in HIV negative than HIV positive patients. Results of this study bring information which will make it possible to pediatrics and nutritionists to adapt better use of $M$. oleifera leaves to combat malnutrition and the follow-up of HIV positive persons and in particular those on antiretroviral treatment.
\end{abstract}

Key words: Moringa oleifera, malnutrition, atherogenic lipids, glycaemia, HIVIAIDS. 


\section{INTRODUCTION}

In developing countries, more than 250 million of children are affected by malnutrition; and 178 million of them who have under the age of five years present growth retardation (Shetty, 2010; OMS, 2011). Food insecurity and lack of access to health care play a major role and explain persistence of malnutrition which is often related to protein-energy and micronutrients deficiencies (West et al, 2006). Acute infections and HIV involve lipids metabolism disturbances and increase cardiovascular diseases risks in patients (Sawadogo et al., 2005; Presles, 2006; Bernal et al., 2008; Crowe et al., 2010). Moreover, antiretroviral therapy of people living with HIVIAIDS, increases coronary diseases frequency and myocardial infarction risk (Bernal et al., 2008; Malvestutto \& Aberg, 2010; Anastos et al., 2010; Melzi et al, 2010; Cournil et al., 2011). Antiretroviral therapy associated with protease inhibitors could provoke insulin resistance and type 2 diabetes development in immunodeficiency patients (Yoon, 2005; Vyas et al., 2010).In Togo, approximately $30 \%$ of children are undernourished and among them $23.5 \%$ who are under five years present growth retardation and $14.3 \%$ are affected by acute form of malnutrition (Ministry of Health, 2009). Moreover, in this country where infant mortality is $9.8 \%$; estimation showed that $0.18 \%$ of the population is HIV positive children (ONU/SIDA 2009). Valorization of edible vegetable such as

\section{MATERIALS AND METHODS}

Study population: Study patients were male and female living in Lomé and they had been regularly followed for 8 months through periodic consultations carried out by Pediatric and Nutritionist Doctors in hospital or health center such as CHU-Tokoin, CMS Casablanca, CMS of Hope-Life-Togo. The test population was selected previously to follow a nutritional recovery program. In this program, Moringa oleifera leaves powder replaced food complement usually proposed in the centers after receiving the Health Ministry's agreement. Before starting the experience, a full explanation of the study was given to the mothers on $M$. oleifera, and a verbal consent was obtained from the selected women. Study patients, old leaves of M. oleifera Lam. (Moringaceae) with high concentration of protein and micronutrients constitute a strategy to combat malnutrition and associated diseases (Idohou-Dossou et al., 2011; Moyo et al., 2011, Tété-Bénissan et al., 2012). Several pharmacological properties are found in $M$. oleifera leaves which are used in traditional medicine against hyperglycemia (Ndong et al., 2007; Jaiswal et al., 2009), hyperlipidemia, hypercholesterolemia (Naznin et al., 2008; Olugbemi et al., 2010), inflammation (Ndong et al., 2007; Nandave et al., 2009; Atawodi et al., 2010; Moyo et al., 2012), cancer and virus (Anwar et al., 2007). They would be glucidic and lipidic metabolism regulator and can be used in HIV positive patients (Ndong et al., 2007; Naznin et al., 2008; Jaiswal et al., 2009; Olugbemi et al., 2010.

The aim of this study was to confirm protein and mineral composition of "Togolese ecotype" of $M$. oleifera leaves powder and to evaluate the effect of daily consumption on atherogenic lipids and glycaemia during nutritional recovery; by analyzing proteins and micronutrients concentrations, evolution of anthropometric parameters, serum total cholesterol, triglycerides, HDL-cholesterol, LDL-cholesterol and glycaemia level in undernourished patients HIV negative and positive. The results will make it possible to achieve guidelines in the way to use $M$. oleifera to combat malnutrition and HIVIAIDS infection.

from 12 months to 8 years and undernourished were separated into two groups. Infants ( $n=51): 25$ HIV negative and 26 HIV positive aged from 12 to 30 months. Children ( $n=54)$ old than 30 months to 8 years including 25 HIV negative and 29 HIV-positive with 14 symptomatic were treated with antiretroviral (ARV) drugs: Zidovudine + Lamivudine + Abacavir. Control group is composed with 14 HIV negative and 13 HIV positive aged from 12 months to 8 years.

Preparation of Moringa oleifera leaves powder: Fresh leaves of $M$. oleifera were collected in Kpessi, 30 $\mathrm{km}$ from Lomé. The identification was confirmed (Togo 05250) in the Botany and Vegetable Ecology Laboratory. Leaves were quickly washed 4 times with 
pure water, and drained for $30 \mathrm{mn}$. They were spread out over paper filter and were dried in laboratory out of direct sunlight and dust for 4 days. The powder was prepared by crushing quite dry leaves in the mill type 3375-E20 (Thomas Scientific ${ }^{\mathrm{TM}}$, the USA), conditioned in plastic pockets and preserved in a dry place.

Determination of nutritional quality of leaves powder: Mineral composition was determined in Geochemistry Laboratory with Atomic Absorption Spectrophotometer type Solaar S2, (Thermo Electron Corporation; Orion, England) after acid mineralization of the sample ash. Total proteins were dosed by Kjeldahl method. Microbiological quality of powder was determined by the research of fungi and bacteria. French standard methods adopted in UEMOA zone (NF V08-051) are used for these germs research.

Incorporation of Moringa oleifera powder in the meals: Powder dose to be incorporated was given according to FAO Recommended Daily Allowance (RDA) (WHO, 2007; Goyens, 2009). Thus, during 15 weeks, infants and children received, $30 \mathrm{~g}$ of powder by day. The daily dose was consumed three times at mealtimes by adding it to sauces or to porridges just before serving them. Regular weekly control was made in hospital or health center to check actual Moringa powder consumption by the patients. In the control group, the meals contained no food supplement.

Blood samples: Peripheral blood (5 ml) samples were obtained at baseline and at the end of the study (15 weeks) through venous puncture in the morning from all patients after 8-10 hours fasting in a dry tube. The samples were transported in a portable ice box to the laboratory within $3 \mathrm{~h}$. After blood clotting, serum was separated by centrifugation. The serum samples conservation was made at $4^{\circ} \mathrm{C}$ and used for different analyzes.

\section{Parameters studied}

\section{RESULTS}

Nutritional and microbiological quality of $M$. oleifera leaves powder: The powder of the leaves of $M$. oleifera prepared contains approximately $38 \mathrm{~g}$ of proteins and $9.7 \mathrm{~g}$ of total minerals by $100 \mathrm{~g}$, with higher concentrations of biogenic minerals, so that the $30 \mathrm{~g}$ gave essential needs for the study patients (Table 1). The microbiological quality of the powder prepared was regarded as satisfactory, compared to the criteria used by French Association of Normalization (AFNOR).

Anthropometric parameters variation : The growth retardation observed in all of HIV negative and HIV
Anthropometric parameters: During 15 weeks, body weight and height were measured every 15 days under Pediatric and Nutritionists Doctors' obligatory controls. Body weight was measured by scales SECA (France): Seca 725 for infant and Seca Robusta 813 for children. Height was measured by resting the infant on his back; children over 2 years in an upright position. Body mass index (BMI) was calculated through the equation weight $(\mathrm{kg}) /$ height $\left(\mathrm{m}^{2}\right)$. The value of the real profit in weight and height was calculated by taking account of the relative profit of patients utilizing $M$. Oleifera and control group (Tété-Bénissan et al., 2012).

Biochemical studies: Two biochemical examinations were performed at baseline and at the end of the study. All data were determined using automated quantitative LISA 500 Plus analyzer (Biocode Hycel, France). Serum Glucose, total cholesterol (TC), triglycerides (TG) and HDL-cholesterol (HDL-C) were quantified using colorimetric enzymatic method with Spinreact reagents kit (Saint Esteve d'en Bas, Girona-Spain). LDL-cholesterol (LDL-C) was determined according to Friedwald and Fredickson formula if triglycerides value is $<4 \mathrm{~g} / \mathrm{l}$. LDL-C $(\mathrm{g} / \mathrm{l})=\mathrm{TC}-(\mathrm{TG} / 5+\mathrm{HDL}-\mathrm{C})$. Atherogenicity index (Al) is calculated according to formula: Atherogenicity index $=\mathrm{LDL}-\mathrm{C} / \mathrm{HDL}-\mathrm{C}$. Serum concentration of parameters was calculated according to formula: Concentration variation $=$ Baseline concentration - End concentration.

Statistical analysis: Data were performed using GraphPad Prism 4 Software. Mean and standard deviations were calculated for quantitative variables in each group and comparisons between groups were made using Mann and Whitney non parametric test or ANOVA. In all the analyses, significance was $5 \%$, ( $p \leq$ 0.05).

positive disappeared after M. oleifera use for 15 weeks. Body Mass Index (BMI) is significantly increased in both patients $(p \leq 0.001)$. In HIV negative, gain in terms of weight was $16.6 \%$ in infants, $11.2 \%$ in children. HIV positive infants gain $4.5 \%$ to $7 \%$ more than HIV positive children. Moreover children treated with antiretroviral drugs had a profit of weight close to the HIV negative children. They gained on average $2.5 \%$ of weight moreover than HIV positive untreated with ARV. HIV negative and positive infants, have significant gain in terms of height in comparison to the children 
Tété-Bénissan et al.... J. Appl. Biosci. 2013. Influence of Moringa oleifera on lipids and glucose in malnourished patients

(approximately 1\%). As for the weight, undernourished and HIV negative infants constituted a group which have best recovered with a gain in terms of height 2.8 times more important than HIV positive untreated children.

Table 1: Nutritional values of Moringa oleifera leaves powder prepared in this study

\begin{tabular}{l|l|l|l|l}
\hline & $\begin{array}{l}\mathbf{m g} / \mathbf{1 0 0 g} \\
\text { of powder }\end{array}$ & $\begin{array}{l}\mathbf{m g} / \mathbf{3 0 ~} \\
\text { of powder }\end{array}$ & $\begin{array}{l}\text { *RDA infants } \\
\text { of } 1-3 \text { years }\end{array}$ & $\begin{array}{l}\text { *RDA children } \\
\text { of 4-9 years }\end{array}$ \\
\hline Total proteins & $\mathbf{3 8 0 0 0} \pm 1500$ & $\mathbf{1 1 4 0 0}$ & $\mathbf{2 0 0 0 0 - 2 3 0 0 0}$ & $\mathbf{3 4 0 0 0}$ \\
\hline Biogenic salts & & & & \\
\hline Calcium & $2448 \pm 152$ & 734,4 & 500 & $700-900$ \\
\hline Potassium & $2060 \pm 119$ & 618 & 800 & 800 \\
\hline Magnesium & $509 \pm 44$ & 152,7 & 80 & $130-200$ \\
\hline Phosphorus & $352 \pm 21$ & 105,6 & 360 & $450-600$ \\
\hline Iron & $19 \pm 5,8$ & 5,7 & 7 & $7-9$ \\
\hline Manganese & $11 \pm 1,1$ & 3,3 & 1 & $1-2$ \\
\hline Copper & $2,14 \pm 0,2$ & 0,645 & 0,8 & $1-1,2$ \\
\hline Zinc & $2,9 \pm 0,5$ & 0,87 & 6 & 7 \\
\hline Selenium & $0,31 \pm 0,02$ & 0,093 & 0,02 & $0,03-0,04$ \\
\hline Total minerals & $\mathbf{9 7 0 0 \pm 3 4 4}$ & $\mathbf{2 9 1 0}$ & & \\
\hline
\end{tabular}

${ }^{*}$ RDA Recommended Daily Allowance (WHO, 2007; Goyens, 2009).

Lipids parameters variation: The increase of the concentrations of total cholesterol (TC), triglycerides (TG), LDL-C in the serum and the decrease of HDL-C are indicators of lipid metabolism disturbance with

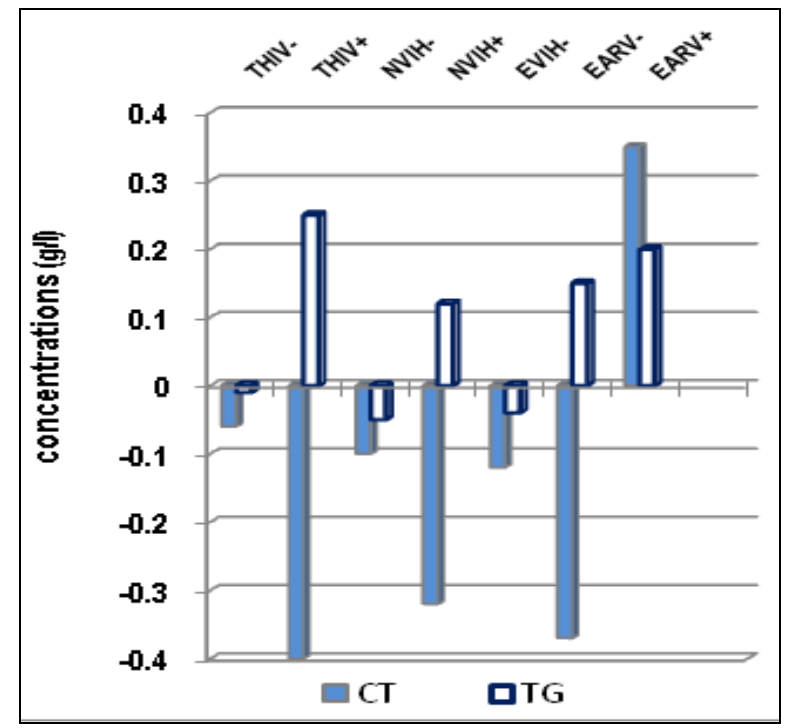

Figure 1: Total cholesterol (CT) and triglycerides (TG) evolution after M. oleifera use. Decrease of CT in: NVIH-, EVIH-, ( $p \leq 0.01)$; $\mathrm{NVIH}+$, EARV-; $(p \leq 0.001)$. Increase of CT in EARV+; $(p \leq$ $0.0001)$. Decrease of TG in HIV negative; ( $p \leq 0.001)$, Increase of higher atherogenic risk. However, a decrease of the TC, TG and LDL-C correlated with increase of the HDL$C$ indicates a positive effect of $M$. oleifera leaves powder consumption.

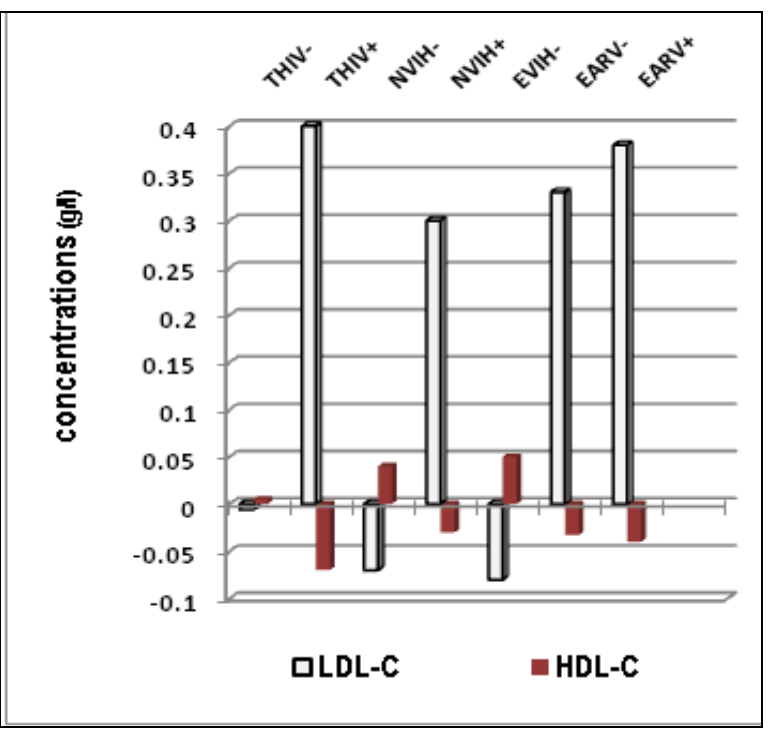

Figure 2: LDL-C and HDL-C after M. oleifera use. Decrease of LDL-C and increase of HDL-C in HIV negative; ( $\leq \leq 0.001$ ). Increase of LDL-C and decrease of HDL-C in HIV positive;

Legend: TVIH- and TVIH+: Control HIV negative and HIV positive; NVIH- and NVIH+: Infants HIV negative and HIV positive; EVIH- : Children HIV negative; EARV- and EARV+: Children ARV- and ARV+. 
In the HIV negative (infants and children), decrease of TC, TG, and LDL-C in the control group was significantly lower ( 5 to 6 times for TC, 4 to 5 times for TG and 7 to 8 times for the LDL-C) than patients utilizing $M$. oleifera powder ( $p \leq 0.01$ ), (figures 1 and 2).However, compared to control group, the increase in
$\mathrm{HDL}-\mathrm{C}$ is 8 to 10 times significantly higher $(p \leq 0.001)$ in both HIV negative patients after M. oleifera powder consumption (figure 2). Consequently, atherogenicity index decreased significantly from 14 to 16 times in patients when compared to the control group that did not use M. oleifera powder ( $p \leq 0.001$ ) (figure 3 ).
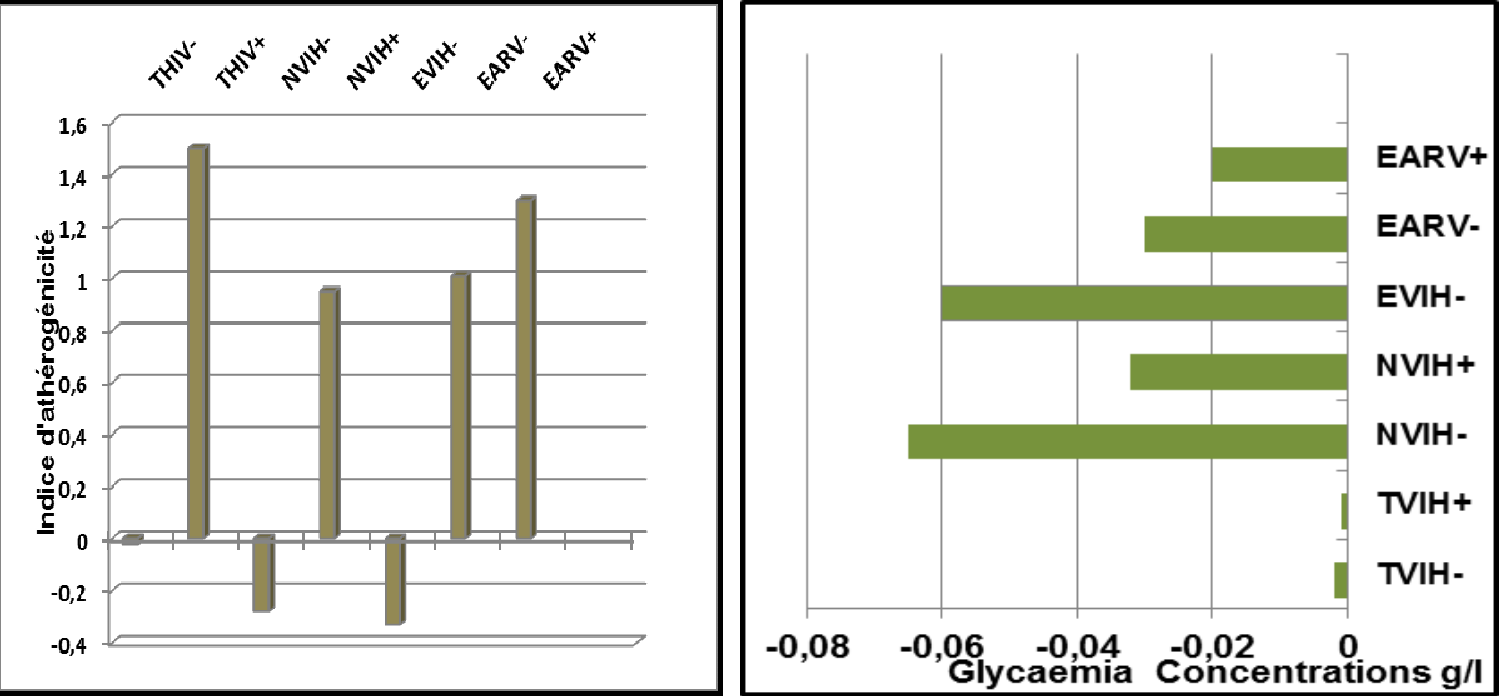

Figure 3: Atherogenicity index evolution of patients after $M$. Figure 4: Evolution of glucose level of patients after $M$. oleifera powder use. Decrease in HIV negative; Increase in HIV oleifera powder use. Decrease of glycaemia in HIV positive $(p \leq 0.0001)$ negative $(p \leq 0.001)$ and HIV positive $(p \leq 0.01)$

Legend: TVIH- and TVIH+: Control HIV negative and HIV positive; $\mathrm{NVIH-}$ and NVIH+: Infants HIV negative and HIV positive; EVIH- : Children HIV negative; EARV- and EARV+ : Children ARV- and ARV+.

In HIV positive patients, significant decrease in TC is practically the same with infants and children untreated with ARV drugs $(-0.32 \mathrm{~g} / \mathrm{l}$ and $-0.37 \mathrm{~g} / \mathrm{l})$ and near to those of control group (- $0.4 \mathrm{~g} / \mathrm{l})$. However, in comparison to the latter, the increase in TC is 7.5 times higher with children treated by ARV ( $p \leq 0.0001)$, (figure 1). Atherogenic lipids (TG, C-LDL) are significantly increased after the use of $M$. oleifera powder by the infants and the children $(p \leq 0.001)$. By comparison children with control group, the increase in triglycerides is 2 times lower and for LDL-C is almost identical $(+0.3 \mathrm{~g} / \mathrm{l}$ vs $0.38 \mathrm{~g} / \mathrm{l})$ (figure 2). The decrease of the HDL-C is near 2.5 times higher inside the control group than inside HIV positive patients treated or untreated by ARV drugs and having consumed $M$. oleifera leaves powder (figure 2). Consequently, the use of M. oleifera induced a weak reduction (- 0.2 to 0.55 ) of atherogenicity index in which the elevation is generated by viral infection (figure 3 ). In detail of the increase of the atherogenic lipids and the decrease of the HDL-C anti atherogenic, it is the group of children treated by the ARV which presents the most important disturbances of the lipid metabolism whatever the parameter considered (CT, TG, LDL-C, HDL-C and Al). These results indicate that $M$. oleifera powder have hypolipidemic effect and impact on atherogenic risk in HIV positive and negative patients. However, the combined effects of viral infection and antiretroviral drugs on the inflammatory processes in patients treated would explain why it is the less reactive group.

Glycaemia variation: The glycaemia level gave indication on glucose metabolism disturbance among patients studied especially in those under antiretroviral therapy. In this study, the use of the M. oleifera leaves powder induced a reduction in glycaemia 2 times more important at the HIV negative than HIV positive. In the group of children with ARV treatment, decrease in glycaemia is the least important. These results show that $M$. oleifera powder has a positive action on the glycemia regulation in patients of the study whatever their serologic statute (figure 4). 


\section{DISCUSSION}

Evolution of the anthropometric parameters and the nutritional status: The consumption of $M$. oleifera powder induced the increase of $\mathrm{BMI}$, with gain of weight and height in HIV negative and HIV positive patients. This is in agreement with Tété-Bénissan et al., (2012) who reported that in undernourished and/or HIV positive patients, $M$. oleifera leaves allow high improvement of nutritional status. Moreover nutritional recovery is more important in patients treated with antiretroviral drugs. Significant positive evolution of anthropometric parameters confirms that $M$. oleifera powder prepared in this study brought adequate proportions of proteins and micronutrients (minerals and vitamins) necessary to both patients. It confirms results of previous studies which showed exceptional nutritional qualities of $M$. oleifera leaves and their effectiveness in malnutrition correction and prevention (Mehta and Fawzi, 2007; de St Sauveur \& Broin, 2010; Moyo et al., 2011; Tété-Bénissan et al., 2012).

Evolution of lipids parameters: Regular consumption of $M$. oleifera powder allowed the decrease of lipids metabolism disturbances caused by infections among undernourished HIV negative infants and children. This induced significant decrease of serum levels of total cholesterol, triglycerides, LDL-C correlated with significant increase in HDL-C. These results confirm $M$. oleifera leaves potential as hypolipidemic, hypocholesterolemic agent which induced the decrease of atherogenic lipids (Naznin et al., 2008; Olugbemi et al., 2010). The lowering effect of $M$. oleifera powder on atherogenic lipids levels is explained by effect of betasitosterol (vegetable sterol which structure is similar to cholesterol) the bioactive phytoconstituent contains in leaves, which induce significant decrease of LDL concentration in plasma (Naznin et al., 2008; Olugbemi et al., 2010). Thus, free cholesterol not fixed at LDL, is purified from peripheral tissues by HDL to the liver where it will be metabolized. HDL with apo A-1 are implied in lecithin cholesteryl acyltransferase (LCAT) and lipoprotein lipase (LP) activation, which facilitate cholesterol transfer and rich triglycerides particles lipolysis. When more triglycerides decrease, more HDL increase; the consequence is a significant decrease of atherogenicity index and protection against atherosclerosis disease in HIV negative and HIV positive (Sawadogo et al., 2005; Presles, 2006; Padmaja et al., 2007; Bernal et al., 2008; Thompson et al., 2008).
This study confirms former work showed quantitative abnormalities of lipids in HIV positive patients. It was noticed in particular, atherogenic lipids (TG and LDL-C) increase and HDL-C (protective) decrease with an important decrease of total cholesterol (hypocholesterolemia) in asymptomatic HIV positive (infants and children); but also the increase (hypercholesterolemia) in HIV positive treated by ARV drugs (Sawadogo et al., 2005; Presles, 2006; Bernal et al., 2008). This explains lipid metabolism disturbances persistence in HIV positive of this study after the regular use of $M$. oleifera powder. At the latter, important inflammatory reactions caused by HIV virus, induce lipids peroxidation in the blood-vessels and involve fast oxidation of LDL-C (Stenvinkel et al., 2005; Tété-Bénissan et al., 2011). This increases their capitation by macrophages which become spumous cells in vascular walls, facilitating atherogenic process (Sawadogo et al., 2005; Stenvinkel, et al., 2005; Crowe et al., 2010). HIV positive have higher hydroperoxid lipid level (oxidized derivatives of the LDL) than HIV negative patients and their total antioxydant capacity is decreased (Stenvinkel, et al., 2005; Crowe et al., 2010). The important decrease of total cholesterol (hypocholesterolemia) observed among HIV positive patients was induced by pro inflammatory cytokines (interleukines, INF and TNF) accelerating esterified cholesterol accumulation in activated macrophages (Sawadogo et al., 2005; Crowe et al., 2010; TétéBénissan et al., 2011). About significant increase of total cholesterol in HIV positive treated with ARV drugs; it was already highlighted by several studies and would be due to a more important disturbance of lipids metabolism (Presles, 2006; Bernal et al., 2008; Anastos et al., 2010; Melzi et al, 2010). Indeed, HIV infection and antiretroviral drugs have independent noxious effects on the blood-vessels and in association, their impact are significantly worsened (Pontes-Cardoso et al., 2007; Bernal et al., 2008). The reduction of HDL-C in HIV positive of this study confirms report of Bernal et al., (2008), Anastos et al., (2010) and would be due partly to Apo A1 synthesis reduction (Tété-Bénissan et al., 2011), because of immunity collapse (Crowe et al., 2010). In this study, increase of triglycerides in HIV positive is in agreement with report of former studies (Presles, 2006; Pontes-Cardoso et al., 2007; Cournil et al., 2011) which showed that hypertriglyceridemia would be explained by cholesterol and triglycerides transport as lipoproteins. There would be a negative 

malnourished patients

correlation between $\mathrm{HDL}$ and triglycerides level (Sawadogo et al., 2005; Tété-Bénissan et al., 2009). Lipoprotein-lipase and hepatic lipase action can be inhibited by metabolic effect of cytokines (IL-1 and TNF) thus disturbing triglycerides rich particles lipolysis and decreasing $\mathrm{HDL}$ quantity. It explains hypertriglyceridemia and HDLC decrease (Stenvinkel, et al., 2005; Kuhlmann et al., 2010). In HIV positive, cytokines effect like INF- alpha $\square$ IL-1, IL-6 and TNFalpha would be correlated with hypertriglyceridemia (Crowe et al., 2010). Consequence is the increase of atherogenicity index and atherogenic risk in HIV positive. Frequencies of cardiovascular diseases and especially coronary diseases whatever the age are increased. However, the control group values show that atherogenic risk reduction in HIV negative and HIV positive patients of this study is primarily due to the use of $M$. oleifera which contains beta-sitosterol, polyphenols and A, C, E vitamins. These results indicate that $M$. oleifera powder has an anti atherogenic action obvious in all studied groups, in spite of its limited effect on disturbances of lipid metabolism in HIV positive patients (Naznin et al., 2008; Olugbemi et al., 2010. Daily consumption of $M$. oleifera powder induced in HIV negative of this study, important reduction of lipid peroxidation and inflammatory cytokines synthesis released by activated macrophages in blood-vessels. This would have allowed a decrease of inflammatory reactions induced by various infections and acute phase proteins synthesis by the liver (Stenvinkel, et al., 2005; Crowe et al., 2010, Tété-Bénissan et al., 2012). Polyphenols, A, C, E vitamins, zinc and selenium in $M$. oleifera powder (Nandave et al., 2009; Atawodi et al., 2010; Moyo et al., 2012) by reducing oxydative stress

\section{CONCLUSION}

Results of this study confirm pharmacological properties of $M$. oleifera leaves which can be used as food complement, lipids and glucose metabolism regulator in HIV positive and HIV negative. Among HIVIAIDS patients, $M$. oleifera leaves induced improvement of nutritional status, accelerated immunological recovery among patients treated with ARV drugs. However, the importance of lipids metabolism disturbances induced by viral infection and ARV drugs, do not seem to be significantly decreased by regular consumption of $M$. oleifera powder in HIV
(Metha \& Fawzi, 2007; Tété-Bénissan et al., 2012), contributed to increase activation of LCAT and hepatic lipase enzymes by reduction of cytokins (IL-1 and TNF) which accelerating lipolysis of triglycerides-rich particles and raising HDL-C quantity. This would increase reverse transport of free cholesterol by HDL from peripheral cells towards liver where it will be metabolized. Positive action of powder components would involve a reuction of atherogenicity index in both patients of this study in particular HIV negative.

Glycaemia evolution: It was reported by several authors that HIV infection induces disturbances of glucose metabolism and an insulin-resistance among patients treated by antiretroviral drugs (Yoon, 2005; Vyas et al., 2010). In the present study, the use of $M$. oleifera leaves induced a reduction of the glycaemia values among HIV positive and HIV negative patients. These results is in agreement with the previous studies which showed that polyphenols (glycosides of quercetin and kaempferol, rutin, gallic acid) were responsible of hypoglycaemia properties, especially quercetin-3glucoside in the leaves which could increase degradation of glucose in the body (Anwar et al., 2007; Ndong et al., 2007; Jaiswal et al., 2009). The results show also the HIV positive patients treated by ARV drugs have no complications of glucose metabolism, induced by the protease inhibitors in their treatment. Indeed, it has shown the increase development risk of diabetes type 2 due to insulin resistance and frequencies of cardiovascular diseases are more important among patients submitted to antiretroviral treatment associated with protease inhibitors (Yoon, 2005; Pontes-Cardoso et al., 2007; Melzi et al., 2010; Vyas et al., 2010).

positive persons. M. oleifera leaves are not drugs, consequently, a specific protocol must be set up for their use in complementary of conventional drugs against the increase of atherogenic risk and the cardiovascular diseases especially in HIVIAIDS patients. This study brings information which will make it possible to nutritionists to adapt better use of medicinal plants, especially $M$. oleifera to combat malnutrition and the follow-up of HIV positive, particular those which have antiretroviral treatment. 


\section{ACKNOWLEDGEMENTS}

The authors thank for their technical assistance, Pediatric Service of Tokoin Hospital, Medical department of NGO Hope Life Togo and Health Center

\section{REFERENCES}

Anastos K, Ndamage F, Lu D, Cohen MH, Shi Q, Lazar J, Bigirimana V, Mutimura E, 2010. Lipoprotein levels and cardiovascular risk in HIV-infected and uninfected Rwandan women. AIDS Res Ther 7:34.

Anwar F, Latif S, Ashraf M, Gilani AH, 2007. Moringa oleifera: a food plant with multiple medicinal uses. Phytother Res 21(1):17-25.

Atawodi SE, Atawodi JC, Idakwo GA, Pfundstein B, Haubner R, Wurtele G, Bartsch H, Owen RW, 2010. Evaluation of the Polyphenol Content and Antioxidant Properties of Methanol Extracts of the Leaves, Stem, and Root Barks of Moringa oleifera Lam. Journal of Medicinal Food 13 (3):710-716.

Bernal E, Masiá M, Padilla S, Gutiérrez F, 2008. Highdensity lipoprotein cholesterol in HIV-infected patients: evidence for an association with HIV1 viral load, antiretroviral therapy status, and regimen composition. AIDS Patient Care STDS 22 (7): 569-75.

Cournil A, Mercier-Deheuvels S, Dupuy AM, Cristol JP, Anaky MA, Rouet F, Fassinou P, Msellati $P$, 2011. Evolution of lipid levels in HIV-infected children treated or not with HAART in Abidjan, Côte d'lvoire. J Trop Pediatr doi: 10.1093/tropej/fmr038. [Accédé le 13 /10/2012].

Crowe SM, Westhorpe CLV, Mukhamedova N, Jaworowski A, Sviridov D, Bukrinsky M, 2010. The macrophage: the intersection between HIV infection and atherosclerosis. J Leukoc Biol 87: 589-598.

De Saint Sauveur A and Broin M, 2010. Moringanews, Moringa Association of Ghana, Produire et transformer les feuilles de Moringa. Editions CTA, CDE; Horizon Gémeno (France), p. 1-69.

Goyens P, 2009. Besoins nutritionnels. In Enfant et nutrition: Guide à l'usage des professionnels. Edition, Office de la Naissance et de l'Enfance (ONE), Benoît Parmentier - Chaussée de Charleroi, 95 - 1060 Bruxelles D/2009/74.80/11. pp 13-32.
Casablanca of Lomé. The realization of this work was possible with financial support of National Institute of Scientific Research of Togo.

Idohou-Dossou N, Diouf A, Gueye AL, Guiro AT, Wade $S$, 2011. Impact of daily consumption of Moringa (Moringa oleifera) dry leaf powder on iron status of Senegalese lactating women. Afric. J. Food. Agr. Nutri. Develop 11 (4): 4985- 4999.

Jaiswal D, Kumar Rai P, Kumar A, Metha S, Watal G, 2009. Effect of Moringa Oleifera Lam. leaves aqueous extract therapy on hyperglycemic rats. J Ethnopharm 123: 392-396.

Kuhlmann I, Minihane AM, Huebbe P, Nebel-A and Rimbach-G, 2010. Apolipoprotein E genotype and hepatitis C, HIV and herpes simplex disease risk: a literature review, Lipids in Health and Disease, 9 (1):8 doi:10.1186/1476511X-9-8 [accédé le 20/10/2012].

Malvestutto CD and Aberg JA, 2010. Coronary heart disease in people infected with HIV. Cleveland Clin J Med 77 (8): 547-556.

Mehta S and Fawzi W, 2007. Effects of vitamins, including vitamin $A$, on HIVIAIDS patients. Vitam Horm 75: 355-83.

Melzi S, Carenzi L, Cossu MV, Passerini S, Capetti A, Rizzardini G, 2010. Lipid Metabolism and Cardiovascular Risk in HIV-1 Infection and HAART: Present and Future Problems. Cholesterol Vol 2010 Article ID 271504, 13p doi:10.1155/2010/271504. [accédé le 13/10/ 2012].

Ministère de la Santé/UNICEF, 2009. Enquête nationale : nutrition et survie des enfants de 0 à 59 mois, pratiques d'alimentation $\mathrm{du}$ nourrisson et du jeune enfant au Togo. Rapport, 82pp.

Moyo B, Masika PJ, Hugo A, Muchenje V, 2011. Nutritional characterization of Moringa (Moringa oleifera Lam.) leaves. African Journal of Biotechnology 10 (60):12925-12933.

Moyo B, Oyedemi S, Masika PJ, Muchenje V, 2012. Polyphenolic content and antioxidant properties of Moringa oleifera leaf extracts and enzymatic activity of liver from goats supplemented with Moringa oleifera leaves/sunflower seed cake. Meat Science 91 
(4): $\quad$ 441-447, $\quad$ doi:10.1016 lj.meatsci.2012.02.029.

Nandave M, Kumar Ojha S, Joshi S, Kumari S, Sing Arya D, 2009. Moringa oleifera Leaf Extract Prevents Isoproterenol-Induced Myocardial Damage in Rats: Evidence for an Antioxidant, Antiperoxidative, and Cardioprotective Intervention. Journal of Medicinal Food 2: 4755.

Naznin A, Mamunur R, Amran Md S, 2008. Comparison of Moringa oleifera leaves extract with Atenolol on Serum triglyceride, Serum cholesterol, Blood glucose, heart weight, body weight in Adrenaline Induced rats. Saudi Journal of Biological Sciences 15(2): 253-258.

Ndong M, Uehara M, Katsumata SI, Kazuharu Suzuki $\mathrm{K}, 2007$. Effects of Oral Administration of Moringa oleifera Lam on Glucose Tolerance in Goto-Kakizaki and Wistar Rats. J Clin Biochem Nutr 40(3): 229-233.

Olugbemi TS, Mutayoba SK, Lekule FP, 2010. Moringa oleifera leaf meal as a hypocholesterolemic agent in laying hen diets. Livestock Research for Rural Development 22 (4): 2010.

ONU/SIDA. West Africa HIVIAIDS Epidemiology and Response Synthesis, implication for prevention. The Global HIVIAIDS Program The world Bank, 2009. http://www.unaids.org/fr/regionscountries/coun tries/togo/.[consulté le 20/10/2012]

Organisation Mondiale de la Santé (OMS), 2011. Statistiques sanitaires mondiales. Rapport 162 $p$

Padmaja N, Ravindra Kumar M, Soya SS, Adithan C, 2007. Common variants of Cholesteryl ester transfer protein gene and their association with lipid parameters in healthy volunteers of Tamilian population. Clin. Chim. Acta, 375(1-2) :140-146.

Pontes-Cardoso LCR; Souza LR; Peraçoli MTS, Pereira PCM, 2007. Cytokine profile and clinical metabolic alterations in HIV-1 infected individuals with and without lipodistrophy. J Venom Anim Toxins incl. Trop. Dis 13 (2):509526.

Presles P, 2006. SIDA : L'infarctus est devenu la première cause de décès. Le Quotidien $d u$ Médecin 7893: 1.

Sawadogo M, Sakandé J, Kabré E, Sougué M, 2005. Profil lipidique au cours de l'infection par le
VIH à Ouagadougou - Burkina Faso : intérêt des marqueurs lipidiques dans le suivi de l'évolution de l'infection à VIH. Ann Biol Clin 63 (5): 507-12.

Shetty $P, 2010$. Les défis posés par la malnutrition: faits et chiffres http://www.scidev.net/fr/features/lesd-fis-pos-s-par-la-malnutrition-faits-etchiffres.html [accédé le 20/09/2012].

Stenvinkel $P$, Ketteler $M$, Johnson RJ, Lindholm B, Pecoits-Filho $R$, Riella $M$, Heimbürger $O$, Cederholm T, Grindt M, 2005. IL-10, IL-6, and TNF- alpha: Central factors in the altered cytokinenetwork of uremia-The good, the bad, and the ugly. Kid Inter 67: 1216-1233.

Tété-Bénissan $A$ and Gbéassor M, 2009. Polymorphisme de l'apo A-IV chez les Togolais: fréquences et influence sur les paramètres lipidiques. J Rech Sci Univ, Lomé (Togo), Série A, 11(1): 61-68.

Tété-Bénissan A, Agbétiafa K, Ségbéna YA, Gbéassor $M, 2011$. Lipid, lipoprotein profile, atherogenic risk and inflammatory status in sickle-cell trait carriers in Togo. Rev. CAMES-Série A 12 (2): 209-215.

Tété-Bénissan A, Quashie ML A, Lawson-Evi K, Kokou K, Gbeassor M, 2012. Nutritional recovery of HIV positive and HIV negative undernourished patients utilizing Moringa oleifera leaves. Journal of Animal \& Plant Sciences 15 (2): 2184-2199.

Thompson A., Di angelantonio E., Sarwar N., Erqou S., Saleheen D, Dullaart RPF, Keavney B, Ye Z, Danesh J, 2008. Association of cholesteryl ester transfer protein genotypes with CETP mass and acivity, lipid levels and coronary risk. Journal of American Medical Association 299 (23) :2777-2788. doi:10.1001/jama.299.23.2777.

Vyas AK, Koster JC, Tzekov A, Hruz PW, 2010. Effets of the HIV protease inhibitor ritonavir on GLUT4 knock-out mice. Journal of Biological Chemistry 265: 36395-36400

West KPJr, Caballero B, Black RE, 2006. Nutrition. In: International Public Health: Diseases, Programs, Systems, and Policies. Merson M, Black RE, Mills AJ, editors. Jones and Bartlett Publishers; Sudbury, Massachusetts. pp187272.

WHO, 2007 Protein and amino acid requirements in human nutrition. Report of a joint 
Tété-Bénissan et al.... J. Appl. Biosci. 2013. Influence of Moringa oleifera on lipids and glucose in malnourished patients

FAO/WHO/UNU Expert Consultation (WHO

Yoon CJ, 2005. Le diabète chez les personnes

Technical Report Series $n^{\circ}$ 935). Geneva: atteintes du VIH. Diabetes Voice 50 (2): 13-15

World Health Organization. 